\title{
Genetic and epigenetic diversity and structure of Phragmites australis from local habitats of the Songnen Prairie using amplified fragment length polymorphism markers
}

\author{
T. Qiu ${ }^{1,2,3}$, L.L. Jiang ${ }^{3}$ and Y.F. Yang ${ }^{1}$
}

${ }^{1}$ Key Laboratory of Vegetation Ecology, Ministry of Education, Institute of Grassland Science, Northeast Normal University, Changchun, Jilin, China

${ }^{2}$ School of Life Sciences, Changchun Normal University,

Changchun, Jilin, China

${ }^{3}$ Key Laboratory of Molecular Epigenetics, Ministry of Education, Northeast Normal University, Changchun, Jilin, China

Corresponding author: Y.F. Yang

E-mail: yangyf601@yahoo.com

Genet. Mol. Res. 15 (3): gmr.15038585

Received March 1, 2016

Accepted April 15, 2016

Published August 18, 2016

DOI http://dx.doi.org/10.4238/gmr.15038585

Copyright $(2016$ The Authors. This is an open-access article distributed under the terms of the Creative Commons Attribution ShareAlike (CC BY-SA) 4.0 License.

ABSTRACT. The genetic and epigenetic diversity and structure of naturally occurring Phragmites australis populations occupying two different habitats on a small spatial scale in the Songnen Prairie in northeastern China were investigated by assessing amplified fragment length polymorphisms (AFLPs) and methylation-sensitive amplified polymorphisms (MSAPs) through fluorescent capillary detection. The two groups of $P$. australis were located in a seasonal waterlogged lowlying and alkalized meadow with a $\mathrm{pH}$ of 8-8.5 and in an alkaline patch 
without accumulated rainwater and with a $\mathrm{pH}$ greater than 10 . These groups showed high levels of genetic diversity at the habitat level based on the percentage of polymorphic bands (90.32, 82.56\%), Nei's gene diversity index $(0.262,0.248)$, and the Shannon diversity index $(0.407,0.383)$. Although little is known about the between-habitat genetic differentiation of $P$. australis on a small spatial scale, our results implied significant genetic differentiation between habitats. Extensive epigenetic diversity within habitats, along with clear differentiation, was found. Specifically, the former habitat (Habitat 1, designated H1) harbored higher levels of genetic and epigenetic diversity than the latter (Habitat 2, designated $\mathrm{H} 2$ ), and population-level diversity was also high. This study represents one of few attempts to predict habitat-based genetic differentiation of reeds on a small scale. These assessments of genetic and epigenetic variation are integral aspects of molecular ecological studies on P. australis. Possible causes for within- and between-habitat genetic and epigenetic variations are discussed.

Key words: AFLP; MSAP; Phragmites australis; Genetic diversity; Genetic differentiation; Habitat

\section{INTRODUCTION}

Phragmites australis (Cav.) Trin. ex Steud. is a widespread wetland grass and clonal species typically occurring in marshes, which are the littoral zones of lakes and rivers. This species is also distributed in drylands and other areas subject to natural abiotic stresses (Lambertini et al., 2008; Kirk et al., 2011; Nada et al., 2015). The high degree of variability and genetic and life history traits of this species may contribute to its cosmopolitan distribution. As such, this species is distributed widely across the Songnen Prairie in northeastern China. $P$. australis often grows as a companion species in alkalized meadows but forms monodominant communities in local low-lying areas or saline-rich/alkaline patches (Li et al., 2009). This species is used as a major forage grass in the Songnen Prairie due to its high level of productivity and high protein content. In addition, it is an ecologically important habitat for ecological renovation and nutrient retention due to its perennial rhizome system and particular adaptation to stress conditions (Yang and Lang, 1998; Koppitz, 1999; Wu et al., 2013).

Among several molecular tools developed to elucidate the molecular ecology of perennial species, amplified fragment length polymorphism (AFLP) analysis has proven to be one of the most suitable and efficient genome-scanning approaches for revealing withinand between-population genetic diversity. This has been determined in various species, including Leymus chinensis (Gong et al., 2007), Hordeum brevisubulatum (Li et al., 2008), Alternanthera philoxeroides (Gao et al., 2010), Fallopia japonica (Richards et al., 2012), Incarvillea younghusbandii (Zhu et al., 2009), and Viola cazorlensis (Herrera and Bazaga, 2008). AFLP, methylation-sensitive amplified polymorphism (MSAP), and specific-sequence amplified polymorphism markers have also been used to analyze genetic/epigenetic diversity in wild barley (H. brevisubulatum) (Shan et al., 2012). In addition, fluorescent AFLP markerbased genotyping performed through capillary gel electrophoresis has improved upon the original AFLP technology and is considered to be a powerful and reliable technique due to its

Genetics and Molecular Research 15 (3): gmr.15038585 
high-resolving power, high sensitivity, and the requirement for small sample (Hasbún et al., 2012).

P. australis found in the Songnen Prairie of northeastern China are interesting because they have evolved easily discernable phenotypes in terms of their leaf, rhizome, and shoot morphology and biomass, which have adapted to various ecological habitats (Yang and Lang, 1998; Yang and Li, 2003). Among these, we focused on two groups of P. australis in two corresponding habitats, i.e., a seasonal waterlogged low-lying and alkalized meadow with a $\mathrm{pH}$ of 8-8.5 (Habitat 1, designated $\mathrm{H1}$ ) and an alkaline patch without accumulated rainwater with a $\mathrm{pH}$ greater than 10 (Habitat 2, designated H2). These two habitats lie within a mosaic of contiguous diverse habitats in the grassland of the Songnen Prairie, which have arisen from severe soil salt-alkalization and vegetative deterioration, particularly during the last 50 years.

Processes resulting in the genetic structuring of plant populations generally include isolation-by-distance and habitat-based genetic differentiation (Mooney et al., 2010). However, little is known about the between-habitat genetic differentiation of $P$. australis on a small spatial scale (Pellegrin and Hauber, 1999; Guo et al., 2003; Gao et al., 2012). A preliminary investigation of the genetic diversity of this reed in the Songnen Prairie showed extensive genetic variability across a certain geographic range ( $\mathrm{Li}$ et al., 2009). However, the within- and between-habitat genetic diversity and differentiation on a small spatial scale in the Songnen Prairie have not yet been studied. In addition to DNA sequence variation, epigenetic mechanisms can cause variation in gene expression and ecologically relevant morphological characteristics and, hence, are recognized as potentially important components of an individual's response to the environment. Variations in DNA methylation, which is the best described epigenetic mechanism and is often heritable in plants, are intriguing; however, only a few studies have used MSAPs, i.e., methylation-sensitive AFLPs to address research questions in wild plant populations (Schrey et al., 2013; Jiao et al., 2015).

In this study, the following issues were addressed to answer fundamental questions at the DNA level for P. australis plants growing in different habitats on a scale of approximately $10 \times 5 \mathrm{~km}$ (Blondel et al., 1999). First, we assessed the levels of genetic diversity within habitats. Second, the degree of genetic differentiation in P. australis between habitats was evaluated. Third, because epigenetic states can be directly disrupted by the environment and can be inherited, epigenetic diversity and structure of populations were determined.

\section{MATERIAL AND METHODS}

\section{Plant materials}

Samples were collected from the Pasture Ecology Research Station of Northeast Normal University, Changling, Jilin Province, in the Songnen Prairie of China $\left(123^{\circ} 45^{\prime} \mathrm{E}\right.$, $\left.44^{\circ} 45^{\prime} \mathrm{N}\right)$. This region exhibits a temperate, semi-arid, and semi-wet monsoon climate. The two groups of $P$. australis are distributed in different habitats with distinct soil-water levels and $\mathrm{pH}$ values. In $\mathrm{H} 1$, the soil is alkalized meadow soil with a $\mathrm{pH}$ of 8-8.5, and water accumulates seasonally during the rainy season. The monodominant reed community grows well and plants are tall because of a plentiful water supply, providing coverage greater than $85 \%$. In $\mathrm{H} 2$, the soil of alkaline patches is hardened with the top soil lost completely and exhibits a $\mathrm{pH}$ greater than 10 . The reeds grow sparsely and in tufts with short stems as a monodominant species, providing community coverage of less than $20 \%$. Each sampled group

Genetics and Molecular Research 15 (3): gmr.15038585 
occurs widely because these habitats lie within a mosaic of various habitats. Fully expanded fresh leaves were collected from 20 randomly selected individual plants of each group, which were distributed in the western, middle, and eastern areas of the research station, within a study area of approximately $10 \times 5 \mathrm{~km}$; thus, three populations were sampled within each habitat. All of the individuals were separated by at least $30 \mathrm{~m}$ to avoid sampling the same gene from several individuals. The numbers of individuals at each site were 6,7, 7, and 7, 6, 7 in $\mathrm{H} 1$ and $\mathrm{H} 2$, respectively. Minimizing the impact of reed collection on local soil erosion was taken into consideration. The leaves were dried using abundant silica gel and were stored at $-20^{\circ} \mathrm{C}$ prior to extraction.

\section{AFLP genotyping and MSAP epi-genotyping}

Genomic DNA was isolated using a modified cetyltrimethylammonium bromide (CTAB) method. A standard AFLP analysis (Vos et al., 1995) was performed, with minor modifications (Wang et al., 2005) and technical improvements, which including the use of fluorescently labeled selective amplification primers (Applied Biosystems Inc., Foster City, CA, USA) and an ABI-automated 3730XL DNA capillary sequencer. The primers that provided the most reliable bands were selected based on the screening results (Table S1). MSAP was performed by following the AFLP protocol, except that the MseI enzyme was replaced with either MspI or HpaII, which identify the same 5'-CCGG sequence but show differential levels of sensitivity to methylation. A ROX-500-labeled internal size standard (Applied Biosystems) was used for each sample. We utilized the GeneMapper v.4.1 software (Applied Biosystems) to collect and score the raw fluorescence data. Noisy sequencer electropherograms were obtained from one plant in several analyses, and this plant was subsequently excluded. We assessed the repeatability of banding patterns by performing two sets of independent AFLP analyses and including only the consistent bands.

All of the reliable bands were scored using the following binary code: 0 for an absent band and 1 for a present band. The markers showing only one non-consensus band were excluded from the data set. Only fragments $\geq 100 \mathrm{bp}$ in size were scored to decrease the effect of size homoplasy. Three different types of MSAP banding patterns were scored, in which the fragments were 1) present in both the EcoRI/HpaII and EcoRI/MspI products, 2) absent in both the EcoRI/HpaII and EcoRI/MspI products, or 3) present only in the EcoRI/ $H p a \mathrm{II}$ or $E c o \mathrm{RI} / M s p \mathrm{I}$ product. The type-(1) pattern corresponds to a non-methylated state, whereas the type-(3) pattern indicates a methylated state, and the type-(2) pattern was treated as a missing score, possibly due to sequence mutation or hypermethylation. We classified each locus as either 'methylation-susceptible' or 'non-methylated' depending on whether the observed proportion of discordant MspI/HpaII scores exceeded a threshold that was set as the probability of a mismatch between the $M s p \mathrm{I}$ and $\mathrm{HpaII}$ scores resulting from errors (Herrera and Bazaga, 2010). All of the scoring was conducted 'blindly', without any details on the samples being available.

\section{Data analyses}

The levels of genetic diversity within each habitat and population were calculated using the Popgene 1.32 programs (Yeh et al., 2000). The genetic diversity parameters determined included the number of alleles per locus $\left(N_{\mathrm{A}}\right)$, the percentage of polymorphic loci $(P)$, Nei's

Genetics and Molecular Research 15 (3): gmr.15038585 
gene diversity index $\left(H_{\mathrm{E}}\right)$, and Shannon information index $(I)$.

Genetic and epigenetic structure was evaluated through analysis of molecular variance (AMOVA) in which the allocation of variance between habitats, among sites, i.e., populations, and within populations was estimated with GENALEX 6.5, using 999 random permutations (Peakall and Smouse, 2006). We employed the msap package in R to analyze the MSAP results (Pérez-Figueroa, 2013). We also conducted a locus-by-locus AMOVA to characterize the epigenetic differentiation at each msap locus using GENALEX.

Genetic relationships between habitats were determined from the values for Nei's genetic distance and the estimate of gene flow $\left(N_{\mathrm{m}}\right)$ obtained using Popgene, and by utilizing the analytical methods mentioned above. The relationships among different individuals were investigated using the principal coordinate analysis ( $\mathrm{PCoA}$ ) program in the msap package to analyze the AFLP data (Pérez-Figueroa, 2013). The Student $t$-test was used to test for differences in $N_{\mathrm{A}}, I$ and $H_{\mathrm{E}}$ between the habitats at $\alpha=0.05$.

\section{RESULTS}

\section{Genetic diversity}

Four AFLP primer pairs produced 992 reliable fragments, with a relatively low scoring error rate. The number of bands per primer pair ranged from 161 to 331 according to the efficiency of each primer, and the levels of polymorphism were high, ranging from 72.63 to $87.01 \%$ (Table 1). At the intra-habitat level, the two groups of $P$. australis showed high levels of genetic diversity. The $P$ bands in $\mathrm{H} 1$ and $\mathrm{H} 2$ were 90.32 and $82.56 \%$, respectively. Likewise, the mean $N_{\mathrm{A}}$ were 1.903 and 1.826; the $H_{\mathrm{E}}$ indices were 0.262 and 0.248 ; and the $I$ indices were 0.407 and 0.383 , respectively, for the reeds in $\mathrm{H} 1$ and $\mathrm{H} 2$ (Table 2). At the population level, the data also showed high levels of genetic diversity according to the average $N_{\mathrm{A}}(1.667,1.574), H_{\mathrm{E}}(0.2332,0.2087), I(0.3516,0.3128)$, and $P(66.73,57.36 \%)$ in $\mathrm{H} 1$ and $\mathrm{H} 2$, respectively.

Table 1. Primer combinations, number of markers, observed levels of polymorphism, and estimates of scoring error rates in the amplified fragment length polymorphism (AFLP) and methylation-sensitive amplified polymorphism (MSAP) analyses.

\begin{tabular}{|c|c|c|c|c|c|c|c|c|}
\hline \multirow{2}{*}{$\begin{array}{l}\text { Primer combination } \\
\text { A. AFLP analysis } \\
\end{array}$} & Total bands & \multicolumn{2}{|r|}{ Polymorphic bands ${ }^{1}$} & \multicolumn{2}{|r|}{ Polymorphic rate (\%) } & \multicolumn{2}{|c|}{ Scoring error rate $(\%)^{2}$} & \\
\hline \\
\hline & & & & & & 0.936 & & \\
\hline $2.4 \mathrm{i}$ & 331 & & 288 & & 87.01 & \multicolumn{2}{|c|}{1.11} & \\
\hline $3.7 \mathrm{a}$ & 161 & & 131 & & 81.37 & \multicolumn{2}{|c|}{0.676} & \\
\hline \multirow{3}{*}{$4.3 \mathrm{c}$} & 310 & & 249 & \multirow{2}{*}{\multicolumn{2}{|c|}{\begin{tabular}{c}
\multicolumn{1}{c}{80.32} \\
Methylation-susceptible markers
\end{tabular}}} & \multicolumn{2}{|c|}{1.15} & \\
\hline & & \multicolumn{2}{|r|}{ Non-methylated markers } & & & & & Estimated probability of errors \\
\hline & & $\mathrm{N}$ & Polymorphic rate $(\%)^{3}$ & $\mathrm{~N}$ & Polymorphic rate $(\%)^{4}$ & HpaII & MspI & HpaII-MspI mismatch ${ }^{5}$ \\
\hline \multicolumn{9}{|l|}{ B. MSAP analysis } \\
\hline $1.5 \mathrm{~h}$ & 318 & 94 & 85.11 & 224 & 80.80 & 1.40 & 1.29 & 0.0265 \\
\hline $2.3 \mathrm{~g}$ & 299 & 101 & 88.12 & 198 & 88.38 & 1.26 & 1.17 & 0.0240 \\
\hline
\end{tabular}

${ }^{1}$ Number of polymorphic bands at the $5 \%$ level. ${ }^{2}$ Calculated from six individual plants that were re-assayed as $100 \mathrm{X}$ (number of discordant scores in two independent analyses) / (number of scored markers $\mathrm{x}$ number of individuals). ${ }^{3} \mathrm{~A}$ non-methylated marker was considered polymorphic if at least two individuals in the sample displayed a variant score. ${ }^{4} \mathrm{~A}$ methylation-susceptible marker was considered polymorphic when both the methylated and non-methylated states occurred in the studied individuals. ${ }^{5}$ Estimated average probability of obtaining discordant EcoRI-HpaII and EcoRI-MspI scores estimated from the scoring error rates for EcoRI-HpaII $\left(=\mathrm{e}_{\mathrm{Hpa}}\right)$ and EcoRI$\operatorname{Msp} \mathrm{I}\left(=\mathrm{e}_{\mathrm{Msp}}\right)$ as $\mathrm{e}_{\mathrm{Hpa}}+\mathrm{e}_{\mathrm{Msp}}-2 \mathrm{e}_{\mathrm{Hpa}} \mathrm{e}_{\mathrm{Msp}}$.

Genetics and Molecular Research 15 (3): gmr.15038585 
Table 2. Genetic diversity in Phragmites australis from two habitats (H1; H2) using AFLP analysis.

\begin{tabular}{l|c|c|c|c|c|c}
\hline & $N_{\mathrm{A}}$ & $H_{\mathrm{E}}$ & $I$-AFLP & $P$-AFLP & $N_{\mathrm{m}}$ & Genetic distance \\
\hline $\mathrm{H} 1$ & 1.903 & 0.2621 & 0.4074 & $90.32 \%$ & & \\
\hline $\mathrm{H} 2$ & 1.826 & 0.2480 & 0.3830 & $82.56 \%$ & & \\
\hline $\mathrm{P}$ value & $<0.001^{*}$ & $0.007^{*}$ & $0.001^{*}$ & & & \\
\hline & & & & & 8.177 & 0.04270 \\
\hline $\mathrm{H} 1$ population mean & 1.667 & 0.2332 & 0.3516 & $66.73 \%$ & & \\
\hline $\mathrm{H} 2$ population mean & 1.574 & 0.2087 & 0.3128 & $57.36 \%$ & & \\
\hline
\end{tabular}

Gene flow $\left(N_{\mathrm{m}}\right)$, genetic distance, and $t$-tests between habitats are shown. $N_{\mathrm{A}}$, mean number of alleles per locus. $H_{\mathrm{E}}$, Nei's gene diversity. $I$, Shannon information index. $P$, percentage of all loci that are polymorphic regardless of allele frequencies. $N_{\mathrm{m}}=$ estimate of gene flow from $G_{\mathrm{ST}}$, e.g., $N_{\mathrm{m}}=0.5\left(1-G_{\mathrm{ST}}\right) / G_{\mathrm{ST}}$. P values for $t$-tests of $N_{\mathrm{A}}, H_{\mathrm{E}}$ and $I$ at $\alpha=0.05$.

\section{Epigenetic diversity}

Among the 617 MSAP loci observed, 422 were methylation-susceptible, $80.80-88.38 \%$ of which were polymorphic, and 195 loci were non-methylated loci, $85.11-88.12 \%$ of which were polymorphic (Table 1). At the intra-habitat level, 13.85 and $12.71 \%$ of the methylationsusceptible were externally cytosine hemimethylated, and 14.91 and $15.02 \%$ were internally cytosine methylated; 21.19 and $22.29 \%$ were unmethylated while the remaining 50.05 and $49.99 \%$ were fully methylated or lost the restriction site resulting from sequence mutation, in $\mathrm{H} 1$ and $\mathrm{H} 2$, respectively. These results suggested that the levels of internal cytosine methylation were higher than the levels of external cytosine hemimethylation, and the total methylation level in $P$. australis was approximately $28 \%$ in both habitats. Approximately 91.41 and $84.93 \%$ of the bands observed in samples from $\mathrm{H} 1$ and $\mathrm{H} 2$ were polymorphic, with $I$ indices of 0.4245 and 0.3984 , respectively (Table 3 ). At the population level, the average values for $P$ were 70.66 and $61.59 \%$, and for $I$ were 0.3712 and 0.3381 in samples from H1 and $\mathrm{H} 2$, respectively.

\section{Genetic and epigenetic structure}

Hierarchical AMOVA of AFLP loci revealed that $5 \%$ of the total molecular variance was attributable to significant differentiation between habitats $(\mathrm{P}<0.001), 6 \%$ was attributable to significant differentiation among populations $(\mathrm{P}<0.001)$, and $89 \%$ was attributable to that within populations $(\mathrm{P}<0.001)$. The value of $\Phi_{\mathrm{PT}}$, which is a measure of population genetic differentiation for binary data and is analogous to $F_{\mathrm{ST}}$, was 0.105 . The genetic distance and the value for gene-flow $\left(N_{\mathrm{m}}\right)$ between the habitats were 0.04270 and 8.177 , respectively. Genetic relationships among individuals and between habitats could be summarized by PCoA, which showed a certain degree of genetic subdivision between the habitats (Figure 1). The $t$-tests, performed to compare genetic diversity, revealed that $N_{\mathrm{A}}(\mathrm{P}<0.001), H_{\mathrm{E}}(\mathrm{P}=0.007)$, and $I$ $(\mathrm{P}=0.001)$ were significantly different between the habitats (Table 2$)$. The AMOVA-based MSAP estimate showed that significant differentiation was present between habitats $(\mathrm{P}<$ 0.001 ), among populations ( $\mathrm{P}<0.001)$, and within populations $(\mathrm{P}<0.001)$, accounting for $2,4$, and $94 \%$ of the total molecular variance, respectively (Table 4$)$. The value for $\Phi_{\mathrm{PT}}$ was 0.06 . The $t$-tests performed to compare epigenetic diversity between the habitats showed that values for $I(\mathrm{P}=0.001)$ were significantly different (Table 3$)$. A locus-by-locus AMOVA showed that 26 MSAP loci were significantly differentiated (Table S2). The level of external cytosine hemimethylation for $P$. australis in $\mathrm{H} 1$ was $1 \%$ more than that for plants from $\mathrm{H} 2$

Genetics and Molecular Research 15 (3): gmr.15038585 
whereas the level of the unmethylated in $\mathrm{H} 1$ was $1 \%$ less than that in $\mathrm{H} 2$. Interestingly, all of the parameters related to the genetic and epigenetic variability of the habitats showed higher values in $\mathrm{H} 1$ than in $\mathrm{H} 2$.

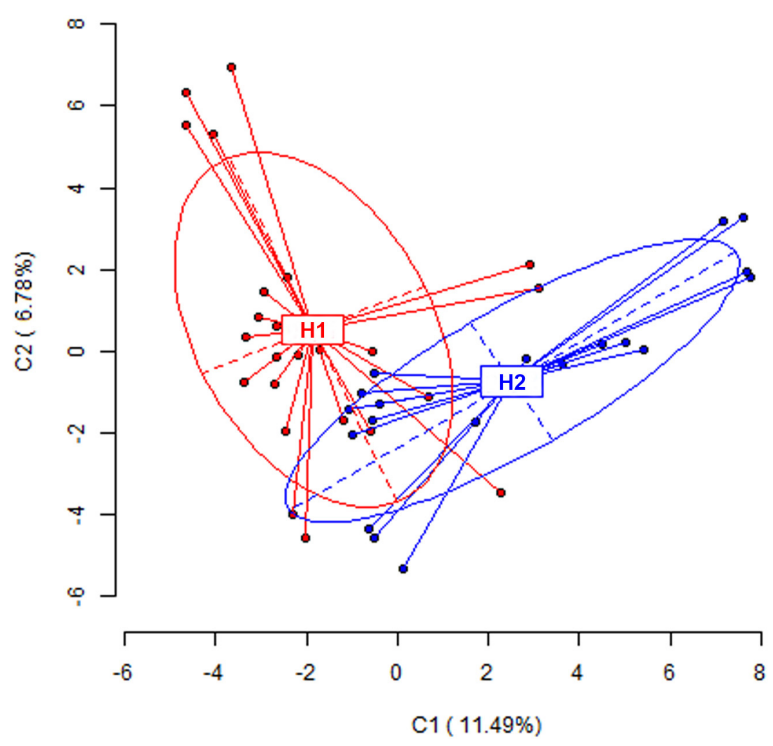

Figure 1. Principal coordinate analysis (PCoA) based on AFLP banding patterns showing the relationships among individuals from two habitats. H1 denotes habitat 1; H2 denotes habitat 2.

Table 3. Epigenetic diversity and methylation levels in Phragmites australis from two habitats (H1; H2) using MSAP analysis.

\begin{tabular}{l|c|c|c|c|c|c}
\hline & $P$-MSAP & $I$-MSAP & \multicolumn{4}{|c}{ Methylation levels } \\
\cline { 4 - 7 } & & & Hemimethylated & Internal cytosine methylation & Non-methylated & Full methylation or absence of target \\
\hline $\mathrm{H} 1$ & $91.41 \%$ & 0.4245 & $13.85 \%$ & $14.91 \%$ & $21.19 \%$ & $50.05 \%$ \\
\hline $\mathrm{H} 2$ & $84.93 \%$ & 0.3984 & $12.71 \%$ & $15.02 \%$ & $22.29 \%$ & $49.99 \%$ \\
\hline $\mathrm{P}$ value & & $0.001^{*}$ & & & & \\
\hline $\mathrm{H} 1$ population mean & $70.66 \%$ & 0.3712 & & & & \\
\hline $\mathrm{H} 2$ population mean & $61.59 \%$ & 0.3381 & & & & \\
\hline
\end{tabular}

$P$, percentage of all loci that are polymorphic regardless of allele frequencies. $I$, Shannon information index.

Table 4. Results of AMOVA within and between Phragmites australis populations from two habitats, i.e., the seasonal waterlogged low-lying meadow $(\mathrm{H} 1)$ and alkaline patch without seasonally accumulated rainwater (H2) for (A) AFLP and (B) MSAP.

\begin{tabular}{|c|c|c|c|c|c|}
\hline Source of variation & d.f. & Sum of squares & Variance components & $\%$ of variation & $\mathrm{P}$ value \\
\hline \multicolumn{6}{|l|}{ A. AFLP } \\
\hline Among habitats & 1 & 339.690 & 6.908 & 5 & $<0.001$ \\
\hline Among populations & 4 & 749.763 & 8.108 & 6 & $<0.001$ \\
\hline Within populations & 39 & 4967.836 & 127.380 & 89 & $<0.001$ \\
\hline Total & 44 & 6057.289 & 142.396 & & \\
\hline \multicolumn{6}{|l|}{ B. MSAP } \\
\hline Among habitats & 1 & 205.536 & 2.608 & 2 & $<0.001$ \\
\hline Among populations & 4 & 591.787 & 4.608 & 4 & $<0.001$ \\
\hline Within populations & 39 & 4438.676 & 113.812 & 94 & $<0.001$ \\
\hline Total & 44 & 5236.000 & 121.028 & & \\
\hline
\end{tabular}

Genetics and Molecular Research 15 (3): gmr.15038585 


\section{DISCUSSION}

We found that levels of genetic polymorphism within habitats and populations were generally high. The mean diversity indices for population-level variation $\left(P, H_{\mathrm{E}}\right.$; Table 2$)$ of $P$. australis were higher than those reported for long-lived perennial herbaceous plants $(P=$ $\left.39.3 \%, H_{\mathrm{E}}=0.084\right)$ by Hamrick and Godt (1990). A comparison of our results $\left(N_{\mathrm{A}}, P, H_{\mathrm{E}}\right.$; Table 2 ) with a summary of 56 mostly terrestrial sexual and asexual species showed that the values for $P$. australis in the present study were higher than those for the 56 species in the previous study $\left(N_{\mathrm{A}}=1.47, P=29.4 \%, H_{\mathrm{E}}=0.103\right)$ (Hamrick and Godt, 1990; Pellegrin and Hauber, 1999). Moreover, genetic variation within populations explained more of the total variation than that between the populations (Table 4). Levels of genetic diversity and its partitioning are correlated with the activity of the reproductive system. Although the reproductive biology of $P$. australis has not been fully resolved, it is clear that Phragmites reproduce both clonally and sexually and are self-compatible. Generally, cross-pollinating plant species show high levels of genetic variation within populations but low levels of divergence between populations, whereas self-pollinating or asexually reproducing species show the opposite pattern (MateuAndrés and de Paco, 2006; Kirk et al., 2011). Therefore, our results indicated that sexual reproduction occurs more frequently than previously thought in $P$. australis. In light of the clear genetic differentiation between populations, inbreeding or clonal reproduction may also have occurred. It has been proposed that $P$. australis can disperse over short and long distances via rhizome fragments or seeds. In addition to dispersal via air or water, seeds may also be ingested and dispersed by herbivores or they may stick to the feathers of migratory birds. Pollen can be carried over long distances by air, particularly during the autumn monsoon in the Songnen Prairie. Because P. australis typically displays clonal growth, somatic mutations, which are maintained within populations, may bea plausible explanation for the high observed genetic diversity (Guo et al., 2003). Population history is another possible factor leading to high levels of genetic polymorphism. P. australis is thought to have been native to the Songnen Prairie as long ago as the early Pleistocene. Historical climatic fluctuation and neotectonic activity could have driven frequent extinctions and recolonizations of local populations, which may have led to multiple founding genotypes or to sexual reproduction between new colonizers and other resident Phragmites genotypes (Zhang and Wang, 2001; Kirk et al., 2011).

We found that the level of genetic differentiation between the habitats is still high. The results of a previous study showed that the average genetic distances between clones from the Po Plain in Italy and geographically distant clones located $1500-2000$ or 2000-2530 km away in several Eurasian countries were 0.042 and 0.044, respectively (Lambertini et al., 2008). The genetic distance observed in our study was 0.0427 , which is similar to the values found in that study. Thus, this suggested that the level of genetic differentiation is generally high, given that our study was conducted within an area of $10 \times 5 \mathrm{~km}$. There are several possible explanations for the pattern of genetic structure observed in the present study, including genetic drift, habitat induction, and mutation. However, it is highly unlikely that genetic drift resulted in this pattern because estimation of the number of migrants $\left(N_{\mathrm{m}}\right)$ gave a relatively high value, and there was substantial between-habitat variance, as demonstrated using the Student $t$-test and AMOVA. A possible explanation for the minimal genetic differences observed in the present study could be the presence of somatic mutations, which are known to occur in several clonal species, including reeds (Connor et al., 1998). It is most likely that habitat selection pressure (i.e., differential alkaline/saline conditions) may have played a major role in the observed genetic

Genetics and Molecular Research 15 (3): gmr.15038585 
diversity. As Kawecki and Ebert (2004) noted, local adaptation is a common result of natural selection on a small spatial scale, even under conditions of high gene flow (Kawecki and Ebert, 2004). In spite of the homogenizing effect of gene-flow between populations over small scales, there are some examples that indicate habitat-based genetic differentiation, supporting the so-called 'divergence-with-gene-flow' model (Shapiro et al., 2006; Mooney et al., 2010).

Assessments of the spectra and structures of epigenetic variation are integral aspects of molecular ecological studies, although few such assessments have been performed on wild plant populations. Because variations in DNA methylation are often heritable and could affect phenotypic outcomes or even evolution (Diez et al., 2014), we examined the epigenetic diversity and structure of $P$. australis in two habitats. Apparently, there is extensive withinpopulation variance due to individual epigenotypic variation, a critical prerequisite for showing microevolutionary potential. Significant epigenetic differentiation presumably underlies these two distinct phenotypes occupying different habitats.

All of the genetic and epigenetic diversity indices assessed in the present study showed the same result, indicating that $P$. australis in $\mathrm{H} 1$ harbor a higher level of genetic and epigenetic diversity than those in $\mathrm{H} 2$, which is congruent with the niche-width variation hypothesis (Valen, 1965). Populations growing in a broader niche (e.g., a more diversified microgeographic habitat, such as H1) are hypothesized to exhibit more variability than populations inhabiting a narrower niche (such as $\mathrm{H} 2$ ).

Taken together, the results of the present study have greatly enhanced our understanding of the genetic and epigenetic basis of $P$. australis from local habitats on a small spatial scale. Accordingly, knowledge gained from genome scans of $P$. australis may provide insight or guidelines for studies of ecological adaptation and for conservation and utilization practices, including ecological revegetation and genetic improvement.

\section{Conflicts of interest}

The authors declare no conflict of interest.

\section{ACKNOWLEDGMENTS}

We appreciate the field assistance of Xue Zhang, Miao Ju, and Wei Zhang (Northeast Normal University). Research supported by the National Natural Science Foundation of China (\#30970457, \#31472134, \#31170208).

\section{REFERENCES}

Blondel J, Dias PC, Perret P, Maistre M, et al. (1999). Selection-based biodiversity at a small spatial scale in a lowdispersing insular bird. Science 285: 1399-1402. http://dx.doi.org/10.1126/science.285.5432.1399

Connor HE, Dawson MI, Keating RD and Gill LS (1998). Chromosome number in Phragmites australis (Arundineae: Gramineae) in New Zealand. N. Z. J. Bot. 36: 465-469. http://dx.doi.org/10.1080/0028825X.1998.9512584

Diez CM, Roessler K and Gaut BS (2014). Epigenetics and plant genome evolution. Curr. Opin. Plant Biol. 18: 1-8. http:// dx.doi.org/10.1016/j.pbi.2013.11.017

Gao L, Geng Y, Li B, Chen J, et al. (2010). Genome-wide DNA methylation alterations of Alternanthera philoxeroides in natural and manipulated habitats: implications for epigenetic regulation of rapid responses to environmental fluctuation and phenotypic variation. Plant Cell Environ. 33: 1820-1827. http://dx.doi.org/10.1111/j.1365-3040.2010.02186.x

Gao L, Tang S, Zhuge L, Nie M, et al. (2012). Spatial genetic structure in natural populations of Phragmites australis in

Genetics and Molecular Research 15 (3): gmr.15038585 
a mosaic of saline habitats in the Yellow River delta, China. PLoS One7: e43334. http://dx.doi.org/10.1371/journal. pone. 0043334

Gong L, Song X, Li M, Guo W, et al. (2007). Extent and pattern of genetic differentiation within and between phenotypic populations of Leymus chinensis (Poaceae) revealed by AFLP analysis. Can. J. Bot. 85: 813-821. http://dx.doi. org/10.1139/B07-072

Guo W, Wang R, Zhou S, Zhang S, et al. (2003). Genetic diversity and clonal structure of Phragmites australis in the Yellow River Delta of China. Biochem. Syst. Ecol. 31: 1093-1109. http://dx.doi.org/10.1016/S0305-1978(03)00032-2

Hamrick JL and Godt MJW (1990). Allozyme diversity in plant species. In: Plant Population Genetics, Breeding, and Genetic Resources (Brown AHD, Clegg MT, Kahler AL and Weir BS, eds.). Sinauer Associates, Sunderland, MA, 43-63.

Hasbún R, Iturra C, Moraga P, Wachtendorff P, et al. (2012). An efficient and reproducible protocol for production of AFLP markers in tree genomes using fluorescent capillary detection. Tree Genet. Genomes 8: 925-931. http://dx.doi. org/10.1007/s11295-011-0463-6

Herrera CM and Bazaga P (2008). Population-genomic approach reveals adaptive floral divergence in discrete populations of a hawk moth-pollinated violet. Mol. Ecol. 17: 5378-5390. http://dx.doi.org/10.1111/j.1365-294X.2008.04004.x

Herrera CM and Bazaga P (2010). Epigenetic differentiation and relationship to adaptive genetic divergence in discrete populations of the violet viola cazorlensis. New Phytol. 187: 867-876. http://dx.doi.org/10.1111/j.14698137.2010.03298.x

Jiao J, Wu J, Lv Z, Sun C, et al. (2015). Methylation-sensitive amplified polymorphism based genome-wide analysis of cytosine methylation profiles in Nicotiana tabacum cultivars. Genet. Mol. Res. 14: 15177-15187. http://dx.doi. org/10.4238/2015.November.25.6

Kawecki TJ and Ebert D (2004). Conceptual issues in local adaptation. Ecol. Lett. 7: 1225-1241. http://dx.doi.org/10.1111/ j.1461-0248.2004.00684.x

Kirk H, Paul J, Straka J and Freeland JR (2011). Long-distance dispersal and high genetic diversity are implicated in the invasive spread of the common reed, Phragmites australis (Poaceae), in northeastern North America. Am. J. Bot. 98: 1180-1190.

Koppitz H (1999). Analysis of genetic diversity among selected populations of Phragmites australis world-wide. Aquat. Bot. 64: 209-221. http://dx.doi.org/10.1016/S0304-3770(99)00051-0

Lambertini C, Gustafsson MHG, Frydenberg J, Speranza M, et al. (2008). Genetic diversity patterns in Phragmites australis at the population, regional and Continental scales. Aquat. Bot. 88: 160-170. http://dx.doi.org/10.1016/j. aquabot.2007.10.002

Li M, Gong L, Tian Q, Hu L, et al. (2009). Clonal genetic diversity and populational genetic differentiation in Phragmites australis distributed in the Songnen Prairie in northeast China as revealed by amplified fragment length polymorphism and sequence-specific amplification polymorphism molecular markers. Ann. Appl. Biol. 154: 43-55. http://dx.doi. org/10.1111/j.1744-7348.2008.00269.x

Li Y, Shan X, Liu X, Hu L, et al. (2008). Utility of the methylation-sensitive amplified polymorphism (MSAP) marker for detection of DNA methylation polymorphism and epigenetic population structure in a wild barley species (Hordeum brevisubulatum). Ecol. Res. 23: 927-930. http://dx.doi.org/10.1007/s11284-007-0459-8

Mateu-Andrés I and de Paco L (2006). Genetic diversity and the reproductive system in related species of antirrhinum. Ann. Bot. 98: 1053-1060. http://dx.doi.org/10.1093/aob/mcl186

Mooney E, Edwards M and Niesenbaum R (2010). Genetic differentiation between sun and shade habitats in populations of Lindera benzoin L. Popul. Ecol. 52: 417-425. http://dx.doi.org/10.1007/s10144-010-0197-6

Nada RM, Khedr AHA, Serag MS, El-NagarNA, et al. (2015). Growth, photosynthesis and stress-inducible genes of Phragmites australis (Cav.) Trin. Ex Steudel from different habitats. Aquat. Bot. 124: 54-62. http://dx.doi. org/10.1016/j.aquabot.2015.03.007

Peakall R and Smouse PE (2006). GENALEX 6: genetic analysis in Excel. Population genetic software for teaching and research. Mol. Ecol. Notes. 6: 288-295. http://dx.doi.org/10.1111/j.1471-8286.2005.01155.x

Pellegrin D and Hauber DP (1999). Isozyme variation among populations of the clonal species, Phragmites australis (Cav.) Trin. ex Steudel. Aquat. Bot. 63: 241-259. http://dx.doi.org/10.1016/S0304-3770(98)00120-X

Pérez-Figueroa A (2013). msap: a tool for the statistical analysis of methylation-sensitive amplified polymorphism data. Mol. Ecol. Resour. 13: 522-527. http://dx.doi.org/10.1111/1755-0998.12064

Richards CL, Schrey AW and Pigliucci M (2012). Invasion of diverse habitats by few Japanese knotweed genotypes is correlated with epigenetic differentiation. Ecol. Lett. 15: 1016-1025. http://dx.doi.org/10.1111/j.14610248.2012.01824.x

Schrey AW, Alvarez M, Foust CM, Kilvitis HJ, et al. (2013). Ecological epigenetics: beyond MS-AFLP. Integr. Comp. Biol. 53: 340-350. http://dx.doi.org/10.1093/icb/ict012

Genetics and Molecular Research 15 (3): gmr.15038585 
Shan XH, Li YD, Liu XM, Wu Y, et al. (2012). Comparative analyses of genetic/epigenetic diversities and structures in a wild barley species (Hordeum brevisubulatum) using MSAP, SSAP and AFLP. Genet. Mol. Res. 11: 2749-2759. http://dx.doi.org/10.4238/2012.August.17.2

Shapiro BJ, Garant D, Wilkin TA, Sheldon BC, et al. (2006). An experimental test of the causes of small-scale phenotypic differentiation in a population of great tits. J. Evol. Biol.19: 176-183. http://dx.doi.org/10.1111/j.14209101.2005.01004.x

Valen LV (1965). Morphological variation and width of ecological niche. Am. Nat. 99: 377-390. http://dx.doi. org/10.1086/282379

Vos P, Hogers R, Bleeker M, Reijans M, et al. (1995). AFLP: a new technique for DNA fingerprinting. Nucleic Acids Res. 23: 4407-4414. http://dx.doi.org/10.1093/nar/23.21.4407

Wang YM, Dong ZY, Zhang ZJ, Lin XY, et al. (2005). Extensive de novo genomic variation in rice induced by introgression from wild rice (Zizania latifolia Griseb). Genetics 170: 1945-1956. http://dx.doi.org/10.1534/genetics.105.040964

Wu J, Wang L, Ma F, Yang J, et al. (2013). Effects of vegetative-periodic-induced rhizosphere variation on the uptake and translocation of metals in Phragmites australis (Cav.) Trin ex. Steudel growing in the Sun island wetland. Ecotoxicology 22: 608-618. http://dx.doi.org/10.1007/s10646-013-1052-2

Yang YF and Lang HQ (1998). A study of population regulation of Phragmites communis as a clonal plant in different ecological conditions. Acta Prat. Sin. 7: 1-9. http://dx.doi.org/10.1137/S0036142995281498

Yang Y and Li J (2003). Biomass allocation and growth analysis on the ramets of Phragmites communis populations in different habitats in the Songnen Plains of China. Ying Yong Sheng Tai XueBao 14: 30-34.

Yeh FC, Yang R, Boyle TJ, Ye Z, et al. (2000). Popgene32, Microsoft windows-based freeware for population genetic analysis. Version 1.32. Molecular Biology and Biotechnology Centre, University of Alberta, Edmonton, Alberta, Canada.

Zhang D and Wang S (2001). The process and driving forces of eco-geo-environmental evolution of the Songnen Plain in northeast China since the Quaternary. Env. Geology 40: 1362-1366. http://dx.doi.org/10.1007/s002540100272

Zhu Y, Geng Y, Tersing T, Liu N, et al. (2009). High genetic differentiation and low genetic diversity in Incarvillea younghusbandii, an endemic plant of Qinghai-Tibetan Plateau, revealed by AFLP markers. Biochem. Syst. Ecol. 37 : 589-596. http://dx.doi.org/10.1016/j.bse.2009.10.007

\section{Supplementary material}

Table S1. Adaptors, pre-selective primers, and primer pairs used for selective amplification in the amplified fragment length polymorphism (AFLP) and methylation-sensitive amplified polymorphism (MSAP) analyses.

Table S2. Summary of significant locus-by-locus tests of differentiation between the habitats for MSAP. An asterisk denotes significant locus-by-locus tests after sequential Bonferroni correction. 